\title{
AGUA, SISTEMAS DE REGADIO Y MITO EN EL VALLE DE ICA, 1900-1960*
}

María Teresa Oré

\section{INTRODUCCION}

La Costa peruana se caracteriza por la presencia de grandes zonas desérticas, en medio de las cuales sobresalen como excepción algunos valles. Es por ello que los antiguos sistemas hidráulicos pre-hispánicos existentes hasta hoy cobran particular importancia, en la medida que permitieron ampliar los escasos recursos de agua existentes en la zona. Posibilitaron así el surgimiento y desarrollo de los valles agrícolas costeños actualmente existentes.

Así, diversos autores, entre ellos Macera, nos llaman la atención sobre este aspecto olvidado por los investigadores actualmente: entender el desarrollo de la agricultura costeña a partir de reconocerla como sociedades hidráulicas. Nos dice lo siguiente:

"Desde Lambayeque hasta Ica, diferentes estudios han puesto en evidencia una mayor extensión y perfeccionamiento de los sistemas de irrigación. Es legítimo, en este caso, hablar de sociedades hidráulicas como las de China, Mesopotamia y Egipto, con poderes políticos que regulaban los tra- 
bajos colectivos consiguientes así como los turnos y derechos en el uso del agua. Los sistemas de reciprocidad debieron ser combinados con un elaborado régimen de redistribuciones estatales. Desarrollos económicos de esta clase resultan imposibles sin el simultáneo desenvolvimiento de ciencias (matemáticas y astronomía) y técnicas (La ingeniería hidráulica)". (1).

Estos sistemas hidráulicos pre-hispánicos adquirieron diversas modalidades no excluyentes entre sí. Entre las más importantes sobresalen las siguientes: hoyas, acueductos y canales de irrigación. Sobre los canales va a girar nuestro trabajo. Fueron la forma más extendida en toda la Costa peruana. Consisten en la derivación de las aguas de superficie de un río o en el aprovechamiento del cauce de varios ríos hacia tierras que no tenían acceso al agua.

Estas construcciones permitieron el desarrollo de la agricultura y el mantenimiento de una gran población. Sin embargo, todavía no se han investigado debidamente sus implicancias sociales. Al haber afluencia de agua solamente en determinados meses del año y en un volumen escaso, la organización social de la agricultura va a asumir características específicas: los cultivos serán uniformes, el agua será dosificada en forma estricta según los turnos y se realizarán una serie de tareas para el mantenimiento y la limpieza anual de los canales que serán realizadas colectivamente. Así, Jurgen Golte nos dice que:

"El ámbito de organización estará básicamente determinado por el ámbito del sistema de riego, el cual podría definirse como un sistema de escasez compartida (2).

Esto significa que la ingerencia de la colectividad en cada agricultor individual deberá ser tanto más fuerte, donde la escasez del agua sea mayor con respecto a la población.

Estas construcciones hidráulicas de origen pre-hispánico sin embargo han sido ampliadas sucesivamente en diferentes momentos, como lo observa Golte; es un trabajo acumulativo. Sin embargo, es en la época Inca cuando la mayor parte de estas construcciones, en especial los canales de riego, fueron ampliados como una forma de consolidar su sistema político, consiguiendo el 
reconocimiento de parte de las poblaciones costeñas recientemente conquistadas.

Cuando los españoles llegaron, se admiraron del conocimiento que aquí existía sobre los sistemas de regadío:

"Los Indios del Alto y Bajo Perú son hidráulicos por naturaleza, conducen por derivación el agua a través de las montañas, de modo que parecería que sube a ellas: hacen sus nivelaciones a la simple vista entre los puntos extremos, dando a la acequia la inclinación correspondiente. Miden con el pie el volumen cúbico del agua que corren y calculan con precisión la cantidad de agua que sale por una toma, en un espacio de tiempo dado, valiéndose para ello de los métodos más primitivos" $(3)$.

Junto a la organización social del sistema de riego se encuentra el significado simbólico y mítico que las poblaciones nativas de la Costa otorgan a estas construcciones hidráulicas pre-hispánicas, significado que está íntimamente vinculado con el agua, como símbolo de vida y de su desarrollo como pueblos agrícolas. De ahí la particular importancia que cobran las leyendas alrededor del agua y de sus sistemas de regadío, así como la ligazón existente entre ambas.

\section{EL CANAL DE LA ACHIRANA EN EL VALLE DE ICA}

La importancia y la antigüedad de este canal la han consignado también diversos cronistas. Dice Garcilaso de la Vega en sus Comentarios Reales:

"Al Valle de Ica, que es fértil como lo son todos aquellos Valles, ennoblecieron todos aquellos reyes Incas con una hermosísima acequia que mandaron sacar de lo alto de la sierra, muy caudalosa de aguas, cuyas corrientes trocaron en contra con admirable artificio, que yendo naturalmente encaminada al levante, las hicieron volver al poniente, porque un rio que pasa por aquel valle traía muy poca agua de verano y padecían los indios mucha esterilidad en sus sembrados..." (3). 
La Achirana presenta un buen trazo que denota un gran conocimiento de ingeniería: recorre todo el valle de Ica y atraviesa precisamente las tierras más fértiles, donde están ubicados la mayoría de pequeños propietarios y los ex-fundos o haciendas más importantes del valle, actualmente cooperativizados. En su recorrido atraviesa los poblados más importantes del valle. Irriga actualmente un total de 17,500 Has. cultivables, que constituyen más de la mitad de las Has. cultivadas del valle de Ica. Su extensión es de $52 \mathrm{~km}$. de recorrido, que van de norte a sur. Se inicia en el poblado de Los Molinos, donde se encuentra la construcción de la bocatoma del canal, y concluye a la altura de Ocucaje. Los poblados que atraviesa - antes caseríos rurales- son: Los Molinos, Santa Rosa, La Tinguiña, Parcona, Los Aquijes, Pueblo Nuevo, Tate, Pampa de Tate (conocida como La Pampa de los Castillos), Santiago, La Venta (altura de Ocucaje), donde termina. Inicialmente, el recorrido del canal llegaba hasta la altura de la comunidad de Tate; la ampliación de su extensión se produjo en 1950. Durante el año, experimenta una gran variabilidad en el volumen de agua: procedente una parte del "agua de avenida" o agua de temporal durante los meses de Diciembre, Enero, Febrero, Marzo. Y la otra procedente de la derivación del agua de Choclococha, que la sueltan los otros meses del año.

La importancia de este canal para la población de la zona se expresa en la vigencia actual de la leyenda de La Achirana.

Entender el papel del canal para el desarrollo agrícola del valle y el valor simbólico que representa para su población es uno de los objetivos del trabajo de investigación que hemos iniciado. Aquí presentaremos algunas de las ideas que han venido surgiendo en el transcurso del trabajo.

Estudios arqueológicos realizados en el canal de La Achirana han encontrado vestigios de diversas plantas de riego, así como restos de tiestos que indicaban que este habría sido construido posiblemente en sus primeros trazos en la cultura Nazca. Además, en las laderas de algunas colinas, junto a su cauce, se han encontrado pequeñas fortalezas o miradores, posiblemente con el fin de evitar ser invadidos por poblaciones vecinas cuando se producían sequías en los valles aledaños.

De estos estudios se podría deducir el orígen pre-inca del canal, aunque, probablemente, en la época incaica este canal haya sido mejorado y ampliado en forma importante, como una forma 
de consolidar el poder y la hegemonía política en esta zona. En la tradición oral de los campesinos del valle, el origen del canal es atribuido en forma particular al Inca Pachacútec y a su ejército, cuando estuvieron en la zona. Ellos afirman que: "es la más importante obra pública que han recibido de todos los gobiernos". Veamos algunos de sus testimonios orales:

"Yo escuchaba que Pachacútec, en ese entonces, era un rey, y que aquí había una india tateña que se llamaba María Chira. Y ella pidió que haga. La Achirana para todos sus peatones que somos nosotros. Entonces, el señor Rey puso unos cuarenta mil hombres, fue así como tomó irrigación para aquí La Achirana. Es por ella que tenemos vida. Oyendo hablar de esa señorita, que seguro sería reina, seguro simpática, yo me encanto, porque pidió vida para su pueblo. A mí me enorgullece, quisiera haberla conocido para adorarla como a una virgencita. Esto es para mis hijos, aquí dejamos la vida, la gloria. Por eso cuando yo me acuerdo de María Chira yo hasta le rezo como rezarle a mi madre. La señorita María Chira es la madre de los pueblos de Tate y Pachacútec. Quien no quiere a una madre no es una persona noble".

(Ignacio López, n. 1900. Comunidad de Tate).

"Cuando el Inca terminó La Achirana se casó con la Tateña, pero cuando vinieron los españoles, él les ofreció un alto así de oro y plata para que no lo mataran, pero los españoles lo mataron. Si no, él estaría vivo hasta hoy y viviría en estas tierras. Antes de morir el Inca, de cólera, mandó encerrar todos sus tesoros en el cerro "Los cerrillos", y algunas noches se ve que de ese cerro baja una bola de oro encendida de fuego y se lleva el agua".

(Víctor Huamán, n. 1891. Caserío Santa Rosa).

De aquí se desprende que La Achirana tiene para los campesinos de la zona no sólo una importancia económica, sino la de legitimarlos como los auténticos poseedores de estas tierras, por ser descendientes de los antiguos constructores del canal. Se identifican con la zona y se definen como pueblos agrícolas. Además, 
simbolizan su unión con el Imperio Incaico a través del "matrimonio" de Pachacútec con María Chira. A través de la leyenda, La Achirana es la afirmación material de su identidad como pueblos agrícolas.

\section{ALGUNOS ELEMENTOS DE ANALISIS: EVOLUCION AGRICOLA DEI, V ALLE DE ICA, 1900-1960}

Es nuestro interés analizar la evolución y el desarrollo agrícola del valle de Ica en torno a su principal y más escaso recurso:

El agua. En tal sentido, cobran especial importancia sus sistemas de regadío (agua superficial y agua subterránea), la organización social que se va a formar alrededor de ellos y la relación que van a guardar con el tipo de cultivos, las formas de propiedad y tenencia de la tierra. Del control y el uso del agua depende el aprovechamiento de las tierras; por ello la importancia vital de la permanente búsqueda de nuevas fuentes hídricas, así como de la administración y distribución de las aguas.

El valle de Ica, situado en medio de extensos arenales, contaba en 1890 con 12,000 has. cultivadas. En 1960 había alcanzado las 28,000 has. cultivadas, según datos de la ONERN.

En esta expansión acelerada de su frontera agrícola, pueden distinguirse dos momentos importantes:

a) 1900-1930: en estos años el valle va a reorientar su economía básicamente hacia el exterior con el cultivo masivo del algodón, que va a desplazar a los cultivos tradicionales de la żona, como eran los viñedos, las menestras y las frutas. La introducción de este cultivo del algodón va a alterar el equilibrio que existía en cuanto a demanda de agua, en relación a los otros productos. Este nuevo cultivo demanda mayor cantidad de agua y especialmente en un determinado mes del año, para evitar que el algodón contraiga plagas que pongan en peligro su producción. Esta urgencia de mayor demanda de agua y el cultivo cada vez en aumento del algodón, tanto de parte de hacendados como de campesinos, obligó al mejoramiento y ampliación de sus sistemas de regadío existentes. En estas obras de construcción y mejoramiento cumplió un papel fundamental el canal de La Achirana, en la medida que la mayor parte de las obras fueron realizadas en él, con lo cual aumentó su disponibilidad y volumen de agua. Sin embargo, aquí hay que añadir un elemento importante; en 
1902 se dio por primera vez en el Perú el Código de Aguas, mediante el cual el control y la administración de las aguas pasaban a manos del Estado. Esto va a marcar una etapa importante en la historia agraria peruana. De alli que todas las obras de ampliación y mejoramiento del sistema de regadío van a ser impulsadas desde el Estado y el control y la administración del agua van a estar a manos de los funcionarios estatales. En todo ello cumplieron un rol importante los ingenieros de aguas, cuya figura más representativa será el Ingeniero Sutton. Este cobrará no sólo una importancia técnica por los proyectos de irrigación que fomentó en toda la Costa peruana, sino, a la vez, una importancia política en el gobierno de Augusto B. Leguía.

Es por ello que todas las obras de mejoramiento del canal de La Achirana fueron realizados por el Estado, así como la administración y control de sus aguas estuvieron a cargo de funcionarios estatales. Marcando con ello una etapa diferente en el valle, en el cual tradicionalmente el control del agua estaba a cargo de los hacendados locales importantes y no existía reglamentación para el uso de sus aguas. El mantenimiento y la limpieza anual del canal estaba a cargo de los indígenas.

b) 1930-1960: es la segunda expansión agrícola importante del valle; con ella se conquista nuevas tierras al desierto, mediante la construcción de importantes obras de irrigación, entre las que destaca la construcción de la Bocatoma en 1932 y la derivación de las aguas de Choclococha para el valle de Ica (1940). Ambas obras serán realizadas a través del canal de La Achirana. Esto supuso un aumento importante en el volumen de agua destinado al valle y el canal alcanza así mayor importancia para la zona. La otra forma mediante la cual se ganaron tierras al desierto fue con la utilización del agua del subsuelo, mediante la construcción de pozos y la introducción de motores para su bombeo. Esto se inició a partir de los años treinta y se intensificó en los cuarenta. Vale la pena señalar que Ica es el departamento del Perú donde se construyeron el mayor número de pozos, llegando hasta un número de 1,000. Sin embargo, el tiempo de duración de los pozos tiene un límite, en la medida que el agua del subsuelo vaya bajando su nivel en proporción al uso que se le dé.

Este tipo de innovacione's y modificaciones en su sistema de regadío existente permitió al valle de Ica conocer la expansión radical de su frontera agrícola en pocos años. 
Las preguntas que surgen son: ¿qué tipo de transformaciones económicas y sociales trajeron todas estas innovaciones? ¿El nuevo cultivo -el algodón- implicó la aparición o consolidación de formas nuevas de explotación como las haciendas modernas? ¿En qué medida este cultivo, masivamente sembrado por campesinos y hacendados, supuso una nueva forma de riego a diferencia de los cultivos tradicionales? ¿Esta dinamización del agro iqueño atrajo el aumento de la fuerza de trabajo eventual $\mathrm{y}$ permanente $\mathrm{y}$ con ello el importante movimiento migratorio desde las zonas serranas colindantes al valle? ¿Cómo repercutieron las transformaciones en el uso y la administración del agua de parte de los funcionarios estatales, en su relación con los hacendados iqueños y los campesinos? ¿Qué proyectos políticos estaban detrás de los grandes proyectos de irrigación para el valle y qué papel jugaron en él los ingenieros de aguas? Finalmente, ¿qué consecuencias trajeron para el valle la introducción de motores para extraer el agua del subsuelo? Estas son algunas de las preguntas que trataremos de responder en el trabajo.

\section{EXPANSION AGRICOLA Y MOVIMIENTOS CAMPESINOS EN EI, VALLE}

Estos dos momentos, de 1900-1930 y de 1930-1960, que corresponden a dos etapas en el desarrollo agrícola del valle, pueden apreciarse de forma nítida a través de dos movimientos sociales importantes en dicho valle: a) el movimiento campesino de Parcona, en 1924; b) La usurpación de las tierras comunales de Pampa de los Castillos, de propiedad de la comunidad de Tate, en 1950. Comparándolos, podemos entender el tipo de transformaciones sociales y económicas que atravezaba el valle y el papel que en él desempeñaron los hacendados, funcionarios estatales y campesinos, así como contraponer sus distintas percepciones de "desarrollo". En forma muy breve, presentaremos ambos movimientos y las preguntas que de allí surgen para su posterior análisis.

A) Las primeras organizaciones y sindicatos campesinos en el valle se van a formar a partir de las "asociaciones de regantes", las cuales van a tener reconocimiento legal y auspicio con la expedición del Código de Aguas del Perú, en 1902, y con el Reglamento de Aguas de 1912. Estas "asociaciones de regantes" orga- 
nizaban el trabajo comunal que tradicionalmente los campesinos realizaban desde tiempos ancestrales en el mantenimiento y la limpieza anual del canal de La Achirana. Además de los trabajos permanentes de reparación y mantenimiento que se hacían durante todo el año, en el mes de octubre se realizaba anualmente la limpieza del cauce y estos trabajos eran previos a la llegada del "agua de avenida" o agua de temporada. La realización de estas tareas era vital para la agricultura del valle y estaba a cargo de los indígenas del lugar. Los hacendados no participaban de estos trabajos, salvo mandando sus peones o capataces. En la tradición oral de los campesinos de la zona, ellos recuerdan como se realizaban estos trabajos:

"Anteriormente, hace unos años, se limpiaba todo comunalmente. Desde los Aquijes para acá, toditita la gente venía para limpiar las bocatomas. Duraba dos, tres meses. Había más de dos mil o tres mil indios y de allí no se escapaba nadie. Allí la ley era la ley. ¿Usted no fue...? Ah, está bien! Venía el agua y usted se quedaba sin regar. Uno estaba dos semanas enteras trabajando, comiendo un poquito, con el fin de avanzar. Yo he ido a pelear con mi papá cuando era chico. Tres semanas íbamos a pelear, desde temprano estábamos y cada vez más cerca, hasta que estábamos por aquí, por Parcona. Y cuando terminábamos, allí a tomar la cachina. El agua venía los primeros días de noviembre y diciembre y allí comenzaban a repicar todas las campanas con gusto. Se hacía la fiesta el día que se terminaba la limpia. Había muchos paisanitos que habian venido de Tate, tenían su guitarra, tocaban... era una alegría máxima, por cuanto habian terminado el cauce".

(Mauricio Pacco, N. 1899, Parcona).

Estas asociaciones y sindicatos de regantes tuvieron un gran dinamismo a partir de 1915 , y contaban con gran reconocimiento $\mathrm{y}$ apoyo de los administradores e ingenieros de aguas. Sus primeros conflictos fueron precisamente por obtener el derecho al uso del agua, y frente a los abusos que los hacendados hacian de este derecho. Estos reclamos fueron aceptados por la Dirección de aguas del valle de Ica, frente a la indignación de los hacendados 
locales, quienes ahora eran "cuestionados" en su derecho al uso del agua. Estas asociaciones de regantes dieron origen en 1920 a la primera Federación campesina del valle de Ica, organización que es disuelta a raíz del movimiento campesino de 1924. Aquí no queremos ahondar en detalles de este movimiento, sino introducir algunas reflexiones y preguntas acerca del contexto que lo rodeó.

¿En qué medida este movimiento grafica una etapa dentro del desarrollo agrícola del valle, caracterizado por el cultivo intensivo del algodón y el mejoramiento de sus sistemas de regadío. A las fricciones tradicionales entre hacendados y campesinos por el derecho al uso del agua, ¿aparecen ahora las fricciones entre los hacendados y los funcionarios estatales por la administración y el control de dicho recurso? ¿Cómo intervienen los campesinos en esa relación? ¿Qué papel jugaron los sindicatos y asociaciones de regantes? ¿Cuál era la concepción de "desarrollo" que manejaban los ingenieros y técnicos, los hacendados y los campesinos? $\mathrm{Y}$ finalmente, ¿cómo se ubica este movimiento campesino, con repercusiones políticas nacionales en el gobierno de Leguía, en este nuevo tipo de conflictos que surgieron por el control y la administración del agua?

B) Posteriormente, en los años cincuenta, varios hacendados se apoderan de extensos terrenos comunales conocidos como "La Pampa de Los Castillos", poblados de extensos huarangales, pero carentes de riego. Estos terrenos eran propiedad de la antigua comunidad de Tate y el agua que conseguian era muy eventual, pues dependía del deshielo de algunos nevados de las zonas altas en determinadas épocas del año. Los hacendados, con la introducción de los pozos y los motores para el bombeo del agua del subsuelo, empiezan a invadir estas tierras comunales y van a surgir nuevos fundos o haciendas en estas tierras. Los campesinos emprenden largos litigios judiciales para recuperarlas, sin embargo las van a perder irremediablemente al cabo de unos años. Como una manera de contener el avance de los hacendados, los campesinos deciden asumir por su cuenta y riesgo la ampliación del canal de La Achirana. De esta forma, poder ellos cultivar sus propios terrenos y frenar así la usurpación de sus tierras.

Este hecho, ¿nos grafica otra etapa dentro del desarrollo agrícola del valle?, caracterizado ahora por la conquista de nuevas 
tierras de cultivo para el algodón, en terrenos que habían sido bosques de huarango o tierras áridas no apropiadas para el cultivo, debido a su carencia de riego. Entonces, la búsqueda de nuevas fuentes de agua, tanto para hacendados como para campesinos, se vuelve vital. ¿Qué significó la introducción de los pozos para la agricultura del valle? ¿En qué medida este recurso, utilizado fundamentalmente por los hacendados (por su alto costo), fue una forma de evadir el control y la administración de las aguas de regadío de parte de los funcionarios estatales? ¿Hasta qué punto el empleo de esta nueva técnica, que contó con el auspicio de la Sociedad Nacional Agraria, escapaba a la "escasez compartida" de la cual Golte nos hablaba al inicio? Pues aquí el recurso agua es permanente, no está sujeto a fluctuaciones y no depende de ninguna ingerencia colectiva, pues es usado en forma particular. Los campesinos, al ampliar el canal de La Achirana, ¿estaban apelando a su legitimidad como descendientes de los antiguos constructores y usuarios del canal?

En esta confrontación entre hacendados y campesinos por tener el acceso al agua y la forma distinta de acceder a este recurso (los pozos de bombeo o la ampliación del ancestral canal de La Achirana) no se ponen en juego solamente distintas modalidades tecnológicas, "modernas versus arcaicas", adoptadas por unos y por otros según sus recursos económicos respectivos: intervienen también elementos ideológicos. ¿En qué medida los campesinos y hacendados participan de la noción de "progreso" o "desarrollo"'? Aunque varíen en sus concepciones, para los hacendados el "desarrollo" estaría asociado a la introducción de nuevas técnicas, mientras que los campesinos lo fundamentan en su conocimiento ancestral de construcción de canales.

En suma, en ambos movimientos sería la vigencia del canal de La Achirana lo que les confirió legitimidad a los campesinos en sus reclamos sobre tierras y aguas. Las características de estos movimientos expresan así el significado múltiple de La Achirana: tecnológico y económico, pero también social e ideológico.

\section{REFLEXIONES FINALES}

No queremos dejar de señalar algunos temas que nos parecen importantes para ser desarrollados en las futuras investigaciones sobre los diversos valles costeños del país; algunos de ellos 
son los siguientes:

a) Determinar la importancia y las implicancias económicas, sociales y políticas que trajo la administración y el control del uso del agua de parte del Estado peruano. ¿Qué consecuencias trajo y como afectó a los intereses de los hacendados locales y de los campesinos? ¿Qué tipo de organizaciones fomentaron la expedición del Código de Aguas de 1902? Papel que desempeñaron las asociaciones de regantes, las juntas de usuarios y la evolución que estas organizaciones han atravesado hasta la actualidad.

b) ¿Qué efectos económicos y políticos tuvo la ejecución de grandes proyectos de irrigación en los valles de la Costa paralelamente a la introducción de nuevos cultivos como el azúcar y el algodón?

c) ¿Qué concepción de "desarrollo" manejaron los técnicos e ingenieros de aguas que impulsaron y llevaron adelante los grandes proyectos de irrigación en la costa? Aquí debemos señalar de manera especial la importancia de un personaje clave que llevó adelante los más importantes proyectos de irrigación, el ingeniero Charles W. Sutton. El rol técnico y político que este ingeniero desempeñó especialmente en el gobierno de Leguía es un tema que debería ser abordado (4).

d) ¿Qué papel desempeñó la técnica en las percepciones sobre el "desarrollo" agrícola del país? ¿Hasta qué punto es un asunto político e ideológico? ¿El "mito del desarrollo" se plasmó en los grandes proyectos de irrigación?

La investigación sobre los sistemas de regadío en el desarrollo agrícola costeño es un aspecto descuidado e ignorado en general por los investigadores. Como afirma Golte, es un aspecto que ha sido dejado a los ingenieros y técnicos especializados y no ha sido retomado por los científicos sociales.

En todo caso, el desafío para iniciar trabajos sobre la importancia de los sistemas de regadío en los valles de la costa es todavía un reto y un vacío en la historia agraria peruana.

Lima, 24 de octubre de 1986.

(*) Este trabajo forma parte del proyecto: "Balances de Investigación en Sistemas Hidráulicos y Andenería Pre-Hispánica". Coordinador del proyecto: Ing. Soledad Bernuy. OPCT. Auspiciado por CONCYTEC y OEA. 


\section{NOTAS}

(1) Macera, Pablo: Visión Histórica del Perú. (Del Paleolitico al Proceso de 1968) p. 56. Editorial Milla Batres, Lima 1978.

(2) Mitre Bartolomé: Las Ruinas del Tiahuanaco. (Recuerdo de

Viaje) Buenos Aires, 1870. Citado por Hans Horkheimer en: Alimentación y Obtención de Alimentos en el Perí Pre-hispánico. p. 140. UNMSM Lima, 1973.

(3) Garcilaso de La Vega: Comentarios Reales. Edición
Buenos Aires. 1943, citado por Hans Horkheimer en op. cit.

(4) Sobre este aspecto, Jürgen Golte tiene reflexiones bastante interesantes, aunque todaviia no publicadas. Hemos le ido un trabajo inédito en el que se comienza a abordar este tema, de Manuel Glave Testino: "Agrarismo, Oncenio y Mercado: La irrigación de Olmos - Lambayeque". PUC. Lima, diciembre 1984. 